\title{
West Nile virus circulation in Emilia-Romagna, Italy: the integrated surveillance system 2009
}

P Angelini (pangelini@regione.emilia-romagna.it) ${ }^{1}$, M Tamba ${ }^{2}$, A C Finarelli ${ }^{1}$, R Bellini ${ }^{3}$, A Albieri ${ }^{3}$, P Bonilauri ${ }^{2}$, F Cavrini ${ }^{4}$,

M Dottori' ${ }^{2}$, P Gaibani ${ }^{4}$, E Martini ${ }^{5}$, A Mattivi $^{1}$, A M Pierro ${ }^{4}$, G Rugna ${ }^{2}$, V Sambri ${ }^{4}$, G Squintani ${ }^{5}$, P Macini ${ }^{1}$

1. Public Health Service, Emilia-Romagna Region, Bologna, Italy

2. Istituto Zooprofilattico Sperimentale della Lombardia e dell'Emilia-Romagna, Brescia, Italy

3. Centro Agricoltura Ambiente "G Nicoli", Crevalcore, Italy

4. Regional Reference Centre for Microbiological Emergencies (CRREM), Microbiology Unit, Azienda Ospedaliero-Universitaria di Bologna, Policlinico S. Orsola-Malpighi, Bologna, Italy

5. Veterinary and Food Hygiene Service, Emilia-Romagna Region, Bologna, Italy

Citation style for this article:

Citation style for this article: Angelini P, Tamba M, Finarelli AC, Bellini R, Albieri A, Bonilauri P, Cavrini F, Dottori M, Gaibani P, Martini E, Mattivi A, Pierro

AM, Rugna G, Sambri V, Squintani G, Macini P. West Nile virus circulation in Emilia-Romagna, Italy: the integrated surveillance system 2009 . Euro Surveill. 2010;15(16):pii=19547. Available online: http://www.eurosurveillance.org/ViewArticle.aspx?Articleld=19547

This article has been published on 22 April 2010

Following a large West Nile virus (WNV) epidemic in north-eastern Italy in 2008, human and animal surveillance activities were implemented in Emilia Romagna. Human surveillance was performed by serology or genome detection on blood and cerebrospinal fluid for all suspected cases suffering from acute meningoencephalitis in the regional territory. Animal surveillance consisted of passive and active surveillance of horses and active surveillance of wild birds and mosquitoes. Between 15 June and 31 October 2009, nine of 78 possible cases of West Nile neuroinvasive disease were confirmed (three fatal). From May to October, 26 cases of neurological West Nile disease were confirmed among 46 horses. The overall incidence of seroconversion among horses in 2009 was 13\%. In 2009, 44 of 1,218 wild birds yielded positive PCR results for WNV infection. The planned veterinary and entomological surveillance actions detected WNV activity from the end of July 2009, about 2-3 weeks before the onset of the first human neurological case. Passive surveillance of horses seems to be an early and suitable tool for the detection of WNV activity, but it will be less sensitive in the future, because an intensive programme of horse vaccination started in June 2009.

\section{Regional integrated surveillance system}

In Italy a national veterinary plan for the surveillance of West Nile virus (WNV) circulation was set up in 2001 under the coordination of the National Reference Centre for Exotic Diseases of animals (CEntro Studi Malattie Esotiche; CESME).

During the late summer of 2008 a large epidemic of WNV infection occurred in north eastern Italy over an area exceeding $7,000 \mathrm{~km}^{2}$, in three regions, including Emilia-Romagna. Twenty-three horse cases and three human cases of the neuroinvasive form of West Nile disease (WND) were confirmed by laboratory tests $[1,2]$. After the first evidence of WNV circulation in horses was found, additional surveillance on horses, birds and mosquitoes was activated.
In Emilia-Romagna the WNV surveillance plan 2009 adopted locally the surveillance measures indicated by the national plan. In particular, among the surveillance activities, the choice was to monitor wild non-migratory birds, such as corvids (the crow family), considered the most sensitive indicators among birds, which can be captured easily. As regards equine surveillance, the regional plan emphasised the education of veterinary practitioners, focusing on the inclusion of WNV in differential diagnosis and the achievement of rapid reporting. A major feature of this plan was to establish an extremely sensitive system of passive surveillance. In addition to passive surveillance, active monitoring of horses was implemented in the area involved in the 2008 outbreak, including Ferrara and the neighbouring provinces [3].

Evidence of WNV circulation in 2008 was found in animals [1,4], humans [5], and mosquitoes. This highlighted the need to implement an integrated surveillance system which would describe the phenomenon comprehensively. Such a system facilitates the collection of data to evaluate spatial distribution and time trends of viral circulation and shares information.

For this reason the 2009 Regional Surveillance Plan implemented activities beyond those of the National Plan, revised the surveillance system of human cases, activated intensive entomological monitoring, and enlarged the surveillance area to involve all the provinces along the Po River.

\section{Human surveillance}

The aim of the human surveillance system was the early detection of infection in humans and the estimation of its diffusion through the systematic analysis of newly emerging clinical cases, in order to manage specific interventions. 
The surveillance was performed throughout the regional territory, from 15 June to 31 October 2009, corresponding to the period of vector activity in EmiliaRomagna and adjusted locally according to weather conditions and vector activity reports. In 2009, the 2008 case definition [6] was extended to include cases of all ages and not only those over 15 years of age.

The human surveillance activity was performed by serology or genome detection on blood and

\section{FIGURE 1}

Map of municipalities with confirmed West Nile

virus circulation and localisation of human West Nile neuroinvasive disease cases by probable infection site,

Emilia-Romagna, Italy, 2009

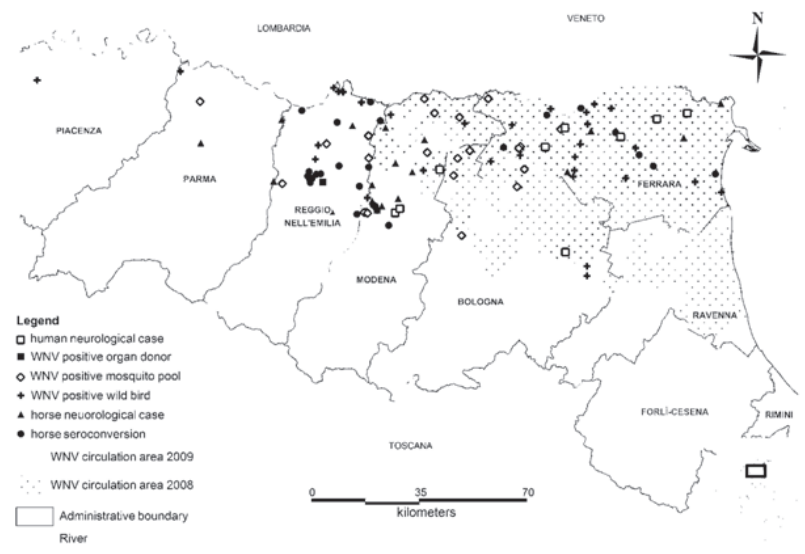

WNV: West Nile virus cerebrospinal fluid for all suspected cases suffering from acute meningoencephalitis in the regional territory. Active surveillance of people who live or work in areas of documented viral circulation was also performed. In addition blood and cerebrospinal fluid samples from subjects living or staying for at least one night in the regional area were sent to the Regional Reference Centre for Microbiological Emergencies (Centro di Riferimento Regionale per le Emergenze Microbiologiche; CRREM). In selected cases, positive specimens were confirmed by the National Health Institute (Istituto Superiore di Sanità; ISS) and by the National Institute for Infectious Diseases (Istituto Nazionale Malattie Infettive; INMI).

From October 2008 to April 2009 a serosurvey performed on 9,177 healthy blood donors living in the province of Ferrara detected a total of $62 \mathrm{lgG}$ positive subjects, corresponding to a seroprevalence of $0.68 \%$.

\section{Animal surveillance \\ The regional veterinary WNV surveillance system was activated from May to October, performing passive and active surveillance on horses and on non-migratory wild birds.}

\section{Horse passive surveillance}

In Italy all suspected signs of WND in horses must be notified to the official veterinary services. Suspected cases were confirmed if resulted positive by reverse transcription - polymerase chain reaction (RT-PCR) performed on central nervous system [7] or to a WNV virus

\section{FIGURE 2}

Distribution of West Nile virus confirmed cases (mosquito pools, birds, horses, and human West Nile neuroinvasive disease) by date, Emilia-Romagna, Italy, July-October 2009

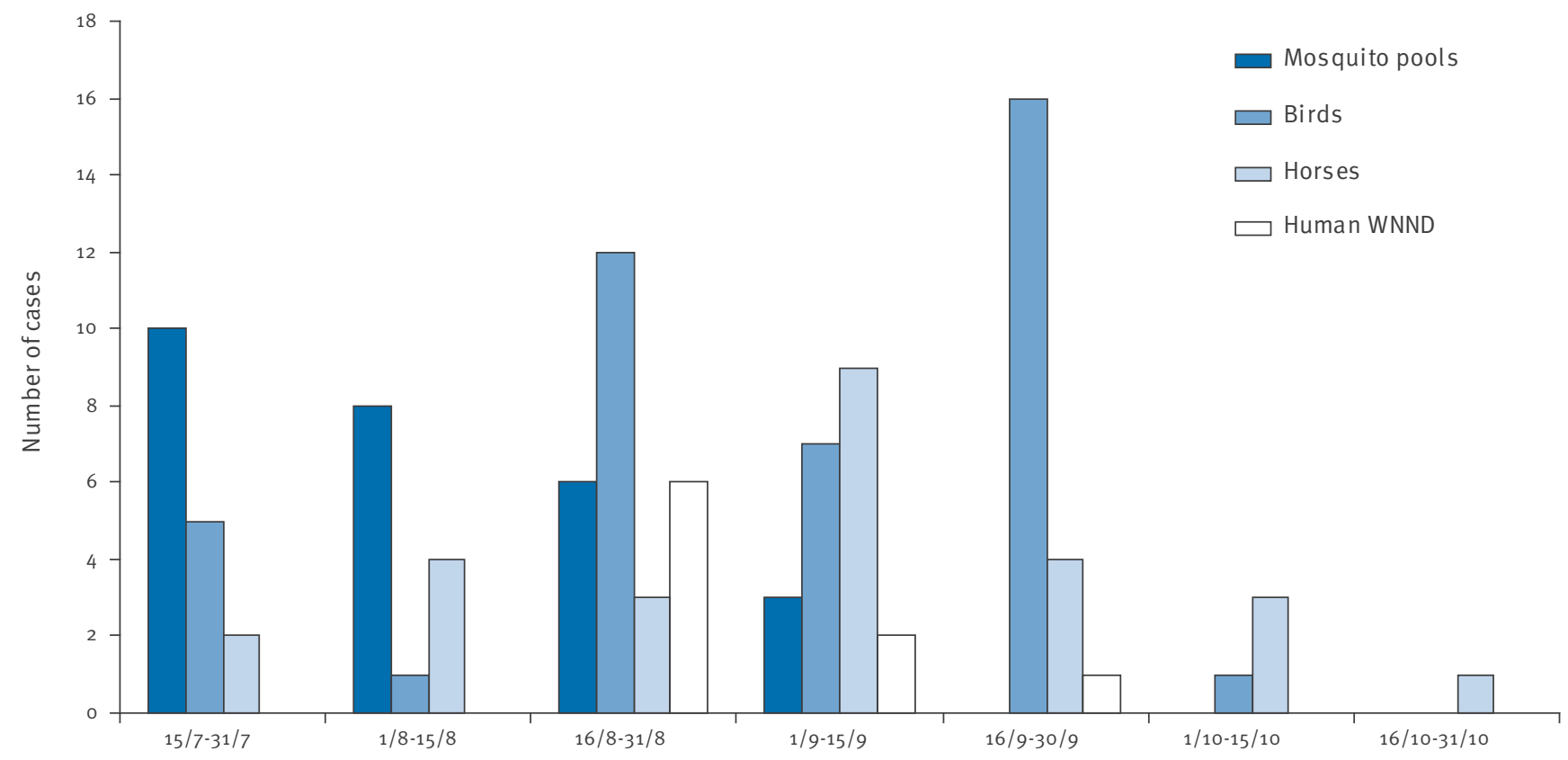

Date 2009

WNND: West Nile neuroinvasive disease

Note: The figure does not include a magpie (found in early May) or a jay (found in early November). 
neutralisation (VN) test (cut-off titre 1:10) in microtitre plates and to IgM enzyme linked immunosorbent assay (ELISA) $[8,9]$.

\section{Horse active surveillance}

In the provinces of Ferrara, Bologna, Modena, Ravenna, and Reggio Emilia, every $1,600 \mathrm{~km}^{2}, 28$ seronegative unvaccinated equine sentinels, sufficient to detect an incidence above $10 \%(\mathrm{Cl} 95 \%)$, were selected in the spring of 2009. They were serologically tested twice after the selection, at the beginning of August and the beginning of September. Samples collected were screened by a home-made competitive ELISA [10]. Positive samples were confirmed by VN and IgM ELISA at the CESME in Teramo. A seroconversion was confirmed if VN titre was at least 1:10 and there was evidence of IgM antibodies.

\section{Wild bird surveillance}

Monitoring was carried out in all the provinces along the Po River, in the plain area of Emilia-Romagna. Every $1,600 \mathrm{~km}^{2}$, a monthly sample of about 40 wild birds caught or shot within specific wildlife population control programmes was collected. Samples of organs (brain, heart, and kidney) of each bird were pooled and examined by RT-PCR [7].

\section{Entomological surveillance}

The surveillance system was based on the weekly to monthly (frequency depends on local resources) collection of mosquitoes in fixed stations and in the sites where birds, humans, or horses signalled WNV activity. Mosquito collections for WNV screening were conducted in six provinces: Ferrara, Ravenna, Bologna, Modena, Reggio Emilia, and Parma, using $92 \mathrm{CO}_{2}$ baited traps positioned in fixed stations. Moreover, mosquito collections were performed promptly using $\mathrm{CO}_{2}$ and gravid traps in sites where positive horses and human cases had been detected.

The surveillance system was activated in the period 15 April to 10 October. Collected mosquitoes were pooled (maximum 200) by species, date, and site of collection and examined by RT-PCR [7]. In addition, overwintered mosquito females were collected during the period 3 March to 8 April by manual aspirator in rural buildings in the area where WNV was active in 2008.

\section{Virological analysis}

Human samples

The detection of WNV genome in human plasma, cerebrospinal fluid, and serum samples obtained from patient suffering from clinical symptoms of meningoecephalitis was performed by an RT-PCR assay based on specific TaqMan probes [7].

Animal samples

In horses RNA was extracted starting from $200 \mu \mathrm{l}$ of serum or whole blood with EDTA as anticoagulant. In birds RNA was extracted from $200 \mu$ of phosphate buffer saline homogenate (about 20\% tissue g / buffer $\mathrm{ml}$ ) of pooled brain, heart and kidney of each analysed bird. In mosquitoes RNA was extracted from $200 \mu \mathrm{l}$ of a maximum of 200 pooled mosquitoes manual grinded by using copper stained beads, in 500-800 $\mu$ l of PBS.

CDNA was submitted to RT-PCR according to the method of Tang and colleagues [7]. Positive samples were confirmed by sequencing of partial nucleocapsin and premembrane protein $M$ amplified according to [11]. Finally from each RT-PCR positive sample WNV was isolated on Vero and RK13 cell lines.

\section{Results}

Results of the integrated surveillance system are mapped in figure 1 , with the sequence of events summarised in figure 2 (July-October), and discussed below.

\section{Human cases}

As of 31 October 2009, nine out of 78 possible cases of West Nile neuroinvasive disease (WNND) notified in Emilia-Romagna have been confirmed (8/9 males; median age 72 years, range: 62-78). Three patients

\section{TABLE 1}

Species distribution of wild birds tested for West Nile virus ( $\mathrm{n}=1,218)$, Emilia-Romagna, Italy, May-October 2009

\begin{tabular}{|c|c|c|c|}
\hline Species & Birds tested & WNV RT-PCR positive & \% WNV positive \\
\hline European magpie (Pica pica) & 607 & 27 & 4.4 \\
\hline Carrion crow (Corvus corone cornix) & 350 & 5 & 1.4 \\
\hline Eurasian jay (Garrulus glandarius) & 96 & 2 & 2 \\
\hline Common blackbird (Turdus merula) & 30 & 0 & - \\
\hline Strigiformes & 11 & 2 & 18 \\
\hline Charadriiformes & 8 & 3 & 38 \\
\hline Other Passeriformes & 7 & 0 & - \\
\hline Other bird orders & 5 & 0 & - \\
\hline Piciformes & 4 & 0 & - \\
\hline Columbiformes & 2 & 0 & - \\
\hline Total & 1,218 & 44 & 3.6 \\
\hline
\end{tabular}

RT-PCR: reverse transcription-polymerase chain reaction; WNV: West Nile virus 


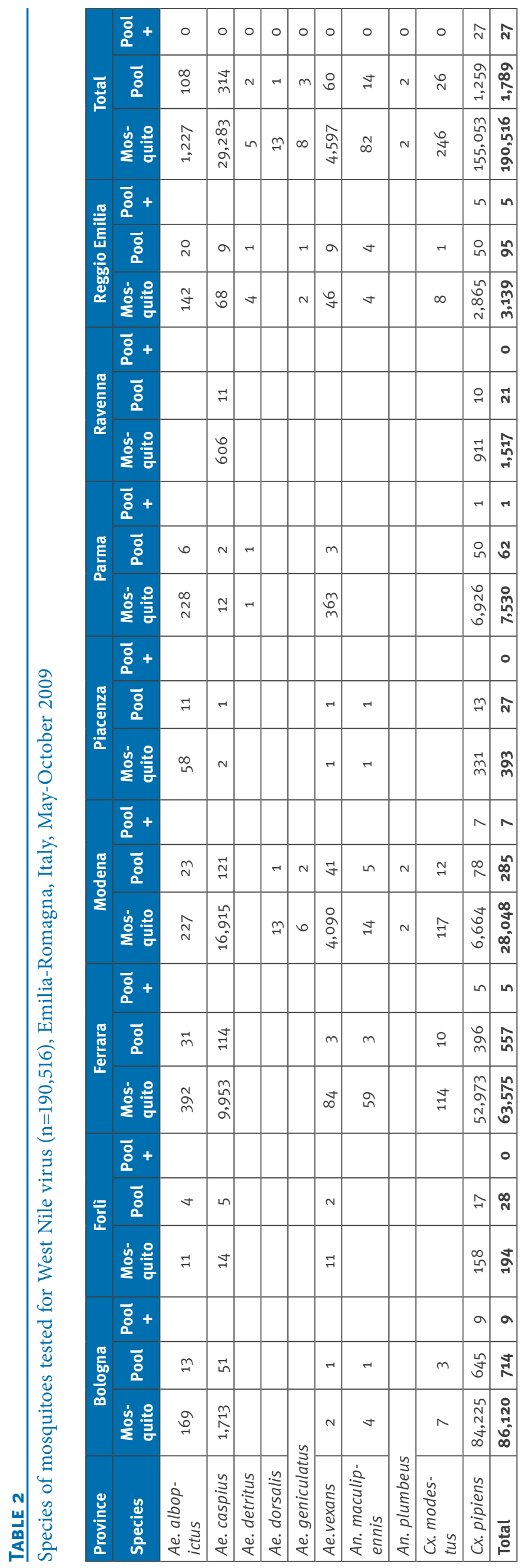

died, two living in Ferrara Province and one in Modena. In addition, not reported in figures, the local health units of Parma and Modena notified two other confirmed cases, both 72 year-old women resident in Mantua province (Lombardy region), treated in hospital in Emilia-Romagna. Another case of infection was that of a 78 year-old female liver donor. Before her death, she had spent two weeks visiting relatives in the WNV affected area (Reggio Emilia).

\section{Horse cases}

Passive surveillance

From May to October, 26 cases of neurological WND were confirmed among 46 horses in which it was suspected. Four of the eight provinces involved in the regional surveillance system had WND cases in horses. The first symptoms in horses were detected in the second half of July in the provinces of Ferrara and Reggio Emilia, but the most cases were notified between midAugust and mid-September (figure 2).

\section{Active surveillance}

Seroconversions in sentinel horses were detected in three provinces (Ferrara, Modena, and Reggio Emilia). Early seroconversions were registered among the controls examined at the beginning of August. Serological controls around the stables with WND cases also confirmed recent WNV infections in the province of Parma. The overall incidence of seroconversion among horses in 2009 was $13 \%$ ( $95 \% \mathrm{Cl}: 10 \%$ to $16 \%$ ), but in Ferrara it was $28 \%$ ( $95 \% \mathrm{Cl}: 19 \%$ to $39 \%)$.

\section{Wild birds}

Six of the eight provinces that took part in the regional surveillance system reported positive birds. In 2009, 44 wild birds out of 1,218 (tested by PCR) yielded positive results for WNV infection. With the exception of a magpie caught in May, positive wild birds were detected from the end of July (figure 2). Most of the infected wild birds were corvids (Pica pica, Corvus corone cornix, Garrulus glandarius), collected within population control programmes in August and September, but WNV was detected also in other species, mainly found dead in wildlife recovery centres (table 1 ).

Table 1. Species distribution of wild birds tested for West Nile V $(n=1,218)$, Emilia-Romagna, Italy, MayOctober 2009

\section{Mosquitoes}

About 190,000 mosquitoes were collected, pooled and tested using PCR $(1,789$ pools of $\leq 200$ individuals/ pool). Culex pipiens were the most abundant species (81.4\%) followed by Aedes caspius (15.4\%) and Aedes vexans $(2.4 \%)$. Other collected species are shown in table 2.

Twenty-seven pools, all consisting of Culex pipiens, yielded positive results for WNV. Early positive pools were collected in the province of Reggio Emilia at the end of July. Minimum infection rates (MIR: (no. of 
positive pools/no. of mosquitoes tested) $\mathrm{x} 1,000$ ) [12] were calculated, with higher MIR values recorded in August in the provinces of Reggio Emilia (3.08) and Modena (1.44).

Referring to the collection of overwintering mosquitoes, three mosquito species were collected: Culex pipiens ( 516 females, 52\%), Anopheles maculipennis s.l. (475 females, 48\%), Culiseta annulata (4 females, $\langle 1 \%)$ : all specimens were tested and yielded negative results.

\section{Conclusions}

The planned veterinary and entomological surveillance actions detected WNV activity from the end of July 2009, about 2-3 weeks before the onset of the first human neurological case. Figure 2 shows that mosquitoes and birds were the first indicators of WNV circulation. The same figure makes it clear that human cases occurred later in the season, as reported elsewhere [6]. Passive surveillance of horses also seems to be an early and suitable tool for the detection of WNV activity, but it will be less sensitive in the future, because an intensive programme of horse vaccination started in June 2009.

More human cases of WNND occurred in 2009 than in 2008 , and three were fatal. It is important to note that in 2008 the epidemic became evident in the late summer (beginning of September). In 2009 the first human cases were detected earlier than 2008. It is likely that increased attention of clinicians to this emerging disease improved the surveillance system sensitivity in 2009.

The circulation of WNV in a large area of the Po plain in two consecutive years shows that this territory is becoming suitable to support WNV establishment and possible endemicity. This indicates a need to organise standard surveillance measures to detect WNV activity early and assess risk to public health.

The results of the entomological surveillance confirm that the $\mathrm{CO}_{2}$ trap is a reliable and valuable tool for early detection of WNV. Culex pipiens, the most abundant mosquito species in the region, is the only vector species incriminated, since no other species collected in the field were found to be infected.

The quick and intensive spread of WNV in the past two years suggests that the whole Po plain may be affected in the future. In forthcoming years, surveillance of wild birds and insects will be used to forecast the extension and spread of WNV. The information gathered will be used to direct or optimise actions intended to prevent virus transmission, such as vector monitoring and control, information campaigns to improve personal protection, and deploy screening tests on blood, tissue, and organs for transplant.
Acknowledgements

The authors would like to thank Ugo Santucci of the Ministry of Employment, Health and Social Policy and Paolo Calistri of CESME for supporting us in managing veterinary surveillance activities. Giovanni Savini of CESME confirmed by VN and PCR all ELISA positive horse sera. The authors also acknowledge the medical and veterinarian practitioners of the local health units involved in epidemic management and all the collaborators in the surveillance system.

\section{References}

1. Calistri P, Giovannini A, Savini G, Monaco F, Bonfanti L, Ceolin $C$, et al. West Nile virus transmission in 2008 in North-Eastern Italy. Zoonosis and Public Health. 2010;57(3):211-9. doi: 10.1111/j.1863-2378.2009.01303.x.

2. Bellini R, Bonilauri P, Angelini P, Albieri A, Veronesi R, Martini $E$, et al. Indication of Culex pipiens as the main vector of West Nile virus spread in Italy in 2008. 2009 national conference "West Nile virus 10 years later" Savannah, GA, USA, 2009, Feb 19-20, p. 31.

3. Macini P, Squintani G, Finarelli AC, Angelini P, Martini E, Tamba $M$, et al. Detection of West Nile virus infection in horses, Italy, September 2008. Euro Surveill. 2008;13(39). pii=18990. Available from: http://www.eurosurveillance.org/ViewArticle. aspx?Articleld=18990.

4. Emilia-Romagna West Nile regional surveillance plan. 2009. Available from: http://www.saluter.it/wcm/saluter/sanitaer/ ssr/assistenza territoriale/Dipartimento sanita pubblica/ documentazione/lk_prevenzione/page/lk_piani/piani/lk/ WND_2009.pdf (Italian version).

5. Rossini G, Cavrini F, Pierro A, Macini P, Finarelli AC, Po C, et al. First human case of West Nile virus neuroinvasive infection in Italy, September 2008 - case report. Euro Surveill. 2008;13(41). pii=19002. Available from: http://www. eurosurveillance.org/ViewArticle.aspx?Articleld=19002.

6. Rizzo C, Vescio F, Declich S, Finarelli AC, Macini P, Mattivi $A$, et al. West Nile virus transmission with human cases in Italy, August - September 2009. Euro Surveill. 2009;14(40). pii=19353. Available from: http://www.eurosurveillance.org/ ViewArticle.aspx?Articleld $=19353$

7. $\quad$ Tang Y, Hapip CA, Liu B, Fang CT. Highly sensitive TaqMan RTPCR assay for detection and quantification of both lineages of West Nile virus RNA. J Clin Virol. 2006;36:177-82.

8. OIE. 2008. Manual of diagnostic tests and vaccines for terrestrial animals. Cap. 2.1.20 West Nile fever. Available from: http://www.oie.int/eng/normes/mmanual/2008/pdf/2.01.20_ WEST_NILE.pdf.

9. Monaco F, Lelli R, Teodori L, Pinoni C, Di Gennaro A, Polci A, et al. Re-emergence of West Nile virus in Italy. Zoonoses and Public Health. 2009; doi: 10.1111/j.1863-2378.2009.01245.x. Abstract online: http://www3.interscience.wiley.com/ journal/122519918/abstract

10. Lelli D, Moreno A, Brocchi E, Sozzi E, Canelli E, Autorino G L, et al. Virus West Nile: caratterizzazione di anticorpi monoclinali e potenziale applicazione nella diagnosi di laboratorio. Proceedings of 3 rd national workshop of veterinary virology. Valenzano (Bari), Italy, Jun 11-12, 2009; p. 63.

11. Lanciotti RS, Kerst AJ, Nasci RS, Godsey MS, Mitchell CJ, Savage HM, et al. Rapid detection of West Nile virus from human clinical specimens, field-collected mosquitoes, and avian samples by a TaqMan reverse transcriptase -PCR assay. J Clin Microbiol. 2000; 38(11):4066-71.

12. Condotta SA, Hunter F, Bidochka MJ. West Nile virus infection rates in pooled mosquito samples and individual. Vector-Borne and Zoonotic Diseases. 2004;4(3):198-203. 